\title{
Radiofrequency catheter ablation of accessory pathways in patients with Ebstein's anomaly: At 8 years of follow-up
}

\author{
Michał Orczykowski ${ }^{1}$, Paweł Derejko ${ }^{1,2}$, Robert Bodalski ${ }^{1}$, Piotr Urbanek ${ }^{1}$, \\ Joanna Zakrzewska-Koperska ${ }^{1}$, Radosław Sierpiński ${ }^{1}$, Katarzyna Kalin ${ }^{1}$, \\ Andrzej Hasiec ${ }^{1}$, Grzegorz Warmiński ${ }^{1}$, Maria Miszczak-Knecht ${ }^{3}$, \\ Katarzyna Bieganowska ${ }^{3}$, Rafał Baranowski ${ }^{1}$, Maria Bilińska ${ }^{1}$, \\ Elżbieta Biernacka ${ }^{4}$, Piotr Hoffman ${ }^{4}$, Łukasz Szumowski ${ }^{1}$ \\ ${ }^{1}$ National Institute of Cardiology, Arrhythmia Department, Warsaw, Poland \\ ${ }^{2}$ Medicover Hospital, Cardiology and Internal Medicine Department, Warsaw, Poland \\ ${ }^{3}$ The Children's Memorial Health Institute, Warsaw, Poland \\ ${ }^{4}$ National Institute of Cardiology, Congenital Heart Diseases Department, Warsaw, Poland
}

\begin{abstract}
Background: Data regarding long-term follow-up of radiofrequency catheter ablation (RFCA) of accessory pathways (APS) in patients with Ebstein's anomaly (EA) are limited. The procedures are challenging due to multiple or wide APs.

Methods: Analysis was performed on clinical and periprocedural data of patients with EA referred to the centre in order to perform catheter ablation of AP. The group consisted of 22 patients (female $40.9 \%$, mean age 33. $6 \pm 19.1$ years). The follow-up utilized electrocardiogram and Holter monitoring.

Results: Twenty-two patients had 33 accessory pathways (8 patients had multiple APs, 11 patients broad AP). Twenty-nine different arrhythmias were ablated: 20 orthodromic atrioventricular reciprocating tachycardia (O-AVRT), 5 antidromic atrioventricular reciprocating tachycardia (A-AVRT), 3 slow/ fast atrioventricular nodal reentry tachycardia (s/f AVNRT) and 1 cavotricuspid-isthmus-dependent atrial flutter (CTI-AFL). In 3 (13.6\%) patients multiple ablation targets for RFCA ablation were observed. The acute procedural success rate after the first RFCA performed was: 100\% for AVNRT, $77.3 \%$ for APs and 50.0\% for CTI-AFL ablation. Follow-up (mean $95.7 \pm 49.8$ months) was completed in $86.4 \%$ of patients. One patient had paroxysmal atrial fibrillation not targeted during ablation. One patient died due to heart failure 12 years after RFCA. Three patients who underwent RFCA of accessory pathways in the mid-1990s were lost in follow-up.

Conclusions: Radiofrequency ablation in patients with EA is challenging but safe and have a high short-term as well as long-term success rate. (Cardiol J 2017; 24, 1: 1-8)
\end{abstract}

Key words: Ebstein's anomaly, accessory pathway, Wolff-Parkinson-White syndrome, catheter ablation

\section{Introduction}

Ebstein's anomaly (EA) is a rare congenital heart disorder that accounts for $<1 \%$ of all patients with congenital heart disease and is characterized by apical displacement of the posterior and septal leaflets of the tricuspid valve with discontinuity of the central fibrous body and septal atrioventricular ring [1]. Arrhythmias are the main symptom in adolescents and adults as well as a major clinical problem [2].

Address for correspondence: Michał Orczykowski, MD, PhD, Institute of Cardiology, Arrhythmia Department, ul. Alpejska 42, 04-628 Warszawa, Poland, e-mail: morczykowski@gazeta.pl 
Wolff-Parkinson-White (WPW) syndrome is more frequently associated with EA than with any other congenital heart defect [3-5]. According to the existing literature, up to $50 \%$ of patients with EA have accessory, frequently multiple pathways (AP) $[4,6,7]$. Abnormal anatomy can also results in activation abnormalities including delayed intraatrial conduction and right bundle branch block $[8,9]$.

According to current guidelines, patients with EA and relevant arrhythmias should be referred for an electrophysiological study followed, if needed, by ablation therapy, or surgical treatment of the arrhythmias in the case of a planned heart surgery [10]. Moreover, the current guidelines concerning the management of patients with supraventricular arrhythmias suggest that EA might present a sudden cardiac death risk factor [11].

Abnormal, fractionated potentials, enlarged cavities of the heart and the presence of multiple APs make the ablation procedure more complicated and challenging.

There is a limited number of reports published on ablation results in patients with EA and WPW. The published data report small groups of patients and relatively short follow-up (from $12 \pm 7$ to $54 \pm 34$ months) [12-14].

The aim of this study was to analyse the safety and efficacy of radiofrequency catheter ablation (RFCA) of accessory pathways in longer follow-ups within one of the largest cohorts of ablated patients with EA.

\section{Methods}

\section{Study patients}

The group consisted of 22 patients with EA and who had been referred to our centre as a tertiary, experienced centre in ablative therapy of congenital heart disease. The patients were relatively young - mean age $33.6 \pm 19.1$ years and predominantly male (58.1\%).

\section{Definitions}

In order to diagnose EA, the apical displacement of the commissure between the septal and posterior leaflets of the tricuspid valve in relation to the anterior mitral valve leaflet by $>8 \mathrm{~mm} / \mathrm{m}^{2}$ body surface area had to be observed [15].

Multiple APs (or an AP with multiple ventricular or atrial insertions) and broad AP were defined as previously described $[16,17]$.

The correct ablation site in patients with broad or multiple AP was identified on the basis of a change in the surface of electrocardiographic (ECG) morphology and/or a delay in the local activation time during radiofrequency $(\mathrm{RF})$ application [17].

Atrial flutter required the cavotricuspid isthmus (CTI-AFL) to be the part of a macroreentrant right atrial tachycardia [5].

The following serious adverse events attributed to catheter ablation were defined: death, atrioventricular block, cardiac perforation, coronary artery involvement or thromboembolic events.

\section{Procedure}

An electrophysiological study was performed in the fasted and sedated state. All patients signed an informed consent form prior to the ablation procedure. Heparin bolus was given at a dosage of 50-100-IU/kg, and after each consecutive hour a heparin bolus of $1000 \mathrm{IU}$. Intracardiac bipolar electrograms as well as 12-lead ECG were recorded digitally. All measurements were performed using onscreen electronic callipers at a sweep speed of 100 $-200 \mathrm{~mm} / \mathrm{s}$ and gain setting of $0.1-0.2 \mathrm{mV} / \mathrm{cm}$. The following catheters, in accordance with the study protocol, were used: (i) a $7 \mathrm{~F}$ steerable, diagnostic quadripolar catheter with 2-5-2 mm inter-electrode spacing (Marinr MCXL, Medtronic, Inc., Minneapolis, MN, USA) placed in the coronary sinus; (ii) ablation catheters: an $8 \mathrm{~F}$ irrigated tip catheter or $8 \mathrm{~mm}$ tip DS catheter. In the mid-1990s, three diagnostic electrodes were used. In use for this study was the 3-dimensional system CARTO XP, CARTO 3 system (Biosense Webster, Inc., Diamond Bar, CA, USA) or EnSite $^{\mathrm{TM}}$ NavX (St. Jude Medical, St. Paul, Mn, USA) and long sheath routinely, since 2002.

\section{Follow-up}

The follow-up data were obtained from hospital and outpatient clinic records. The evaluation of the patients comprised: physical examination, a 12-lead ECG, echocardiography and Holter monitoring performed in all patients a minimum of 4 times.

Holter monitoring was performed at intervals of 6 months during the first year subsequent to the last successful RFCA procedure and at intervals of 12 months thereafter.

Patients were systematically asked about symptoms of recurrent arrhythmias and encouraged to notify the clinic in the case of recurrence at any time during the follow-up period. Patients with recurrent arrhythmia were offered a repeat ablation.

\section{Statistical analysis}

Categorical variables were expressed as numbers and percentages, continuous variables as median and range or mean with 1 standard de- 
Table 1. Patient characteristics.

\begin{tabular}{|c|c|c|c|c|c|c|}
\hline Pt. & Sex & Age & $\begin{array}{c}\text { Age of first } \\
\text { arrhythmia episode }\end{array}$ & Ablation targets & $\begin{array}{l}\text { Total no. } \\
\text { of ablations }\end{array}$ & $\begin{array}{l}\text { Reason for } \\
\text { multiple procedures }\end{array}$ \\
\hline 1 & $M$ & 18 & 16 & 1 broad AP, A-AVRT & 3 & $\mathrm{AP}$ \\
\hline 2 & $\mathrm{~F}$ & 42 & 7 & 2 APs, O-AVRT & 1 & - \\
\hline 3 & M & 33 & 1 & 2 APs, O-AVRT & 1 & - \\
\hline 4 & $\mathrm{~F}$ & 13 & 3 & 1 broad AP, O-AVRT & 1 & - \\
\hline 5 & $\mathrm{~F}$ & 13 & 1 & $\begin{array}{c}1 \text { broad AP, O-AVRT, } \\
\text { s/f AVNRT }\end{array}$ & 1 & - \\
\hline 6 & M & 18 & NA & 1 broad AP, O-AVRT & 1 & - \\
\hline 7 & $M$ & 68 & 5 & $\begin{array}{c}1 \text { broad AP, O-AVRT, } \\
\text { s/f AVNRT }\end{array}$ & 3 & AP \\
\hline 8 & M & 53 & NA & $1 \mathrm{AP}, \mathrm{O}-\mathrm{AVRT}$ & 1 & - \\
\hline 9 & $\mathrm{~F}$ & 49 & NA & $\begin{array}{c}2 \text { APs, } 1 \text { broad AP, } \\
\text { O-AVRT }\end{array}$ & 1 & - \\
\hline 10 & M & 27 & 6 & 2 APs, O-AVRT & 3 & $A P$ \\
\hline 11 & $\mathrm{~F}$ & 47 & NA & $\begin{array}{c}1 \text { AP, O-AVRT, } \\
\text { s/f AVNRT, CTI-AFL }\end{array}$ & 2 & CTI-AFL \\
\hline 12 & $\mathrm{~F}$ & 18 & 1 & 2 APs, O-AVRT & 1 & - \\
\hline 13 & $\mathrm{~F}$ & 74 & NA & 1 broad AP, O-AVRT & 3 & AP \\
\hline 14 & $M$ & 14 & 11 & $\begin{array}{l}2 \text { APs, } 1 \text { broad, } \\
\text { O-AVRT, A-AVRT }\end{array}$ & 1 & - \\
\hline 15 & $\mathrm{~F}$ & 53 & 13 & $1 \mathrm{AP}, \mathrm{O}-\mathrm{AVRT}$ & 1 & - \\
\hline 16 & $M$ & 25 & NA & $1 \mathrm{AP}, \mathrm{A}-\mathrm{AVRT}$ & 1 & - \\
\hline 17 & $\mathrm{~F}$ & 60 & NA & 1 broad AP, O-AVRT & 1 & - \\
\hline 18 & M & 34 & NA & 1 broad AP, O-AVRT & 3 & AP \\
\hline 19 & $M$ & 29 & NA & $1 \mathrm{AP}, \mathrm{O}-\mathrm{AVRT}$ & 2 & $\mathrm{AP}$ \\
\hline 20 & $M$ & 19 & NA & $3 \mathrm{APs}$ & 1 & - \\
\hline 21 & $M$ & 17 & NA & $\begin{array}{c}3 \text { APs, A-AVRT, } \\
\text { O-AVRT }\end{array}$ & 4 & $A P$ \\
\hline 22 & M & 16 & NA & 1 broad AP & 5 & $A P$ \\
\hline
\end{tabular}

A-AVRT — antidromic atrioventricular reentrant tachycardia; AP — accessory pathway; AV — atrioventricular node; s/f AVNRT — slow/fast atrioventricular nodal reentrant tachycardia; CTI-AFL — cavotricuspid isthmus-dependent atrial flutter; $\mathrm{F}-\mathrm{female}$; $\mathrm{M}-\mathrm{male}$; NA - not available; O-AVRT — orthodromic atrioventricular reentrant tachycardia

viation, respectively. Categorical variables were compared with the use of $\chi^{2}$ test. A p value $<0.05$ was considered statistically significant. Analyses were performed using SPSS software.

\section{Results}

\section{Study population}

Twenty-two patients with EA (female $40.9 \%$, mean age $33.6 \pm 19.1$ years) were admitted to a centre experienced in ablative therapy of congenital heart disease in order to perform RFCA of accessory pathways between 1993 and 2015 (Tables 1,2).

The patients' evaluation comprised of clinical history, physical examination, a 12-lead ECG,
Table 2. Procedural data.

\begin{tabular}{lc}
\hline Parameters & AP $(\mathbf{n}=22)$ \\
\hline Previous cardiac surgery & $4(18.2 \%)$ \\
Age at first ablation [years] & $33.6 \pm 19.1$ \\
One ablation, in our lab & $14(63.6 \%)$ \\
Two ablations in our lab & $5(22.8 \%)$ \\
Three ablations in our lab & $3(13.6 \%)$ \\
Number of ablationsoutside our centre & $10(45.5 \%)$ \\
Two ablations outside our centre & $5(22.8 \%)$ \\
Total number of interventions & 40 \\
3D system in our lab & $18(81.8 \%)$ \\
Long sheath in our lab & $15(62.5 \%)$ \\
Long-term success & $95.5 \%$ \\
\hline AP - accessory pathway; 3D - three-dimensional &
\end{tabular}




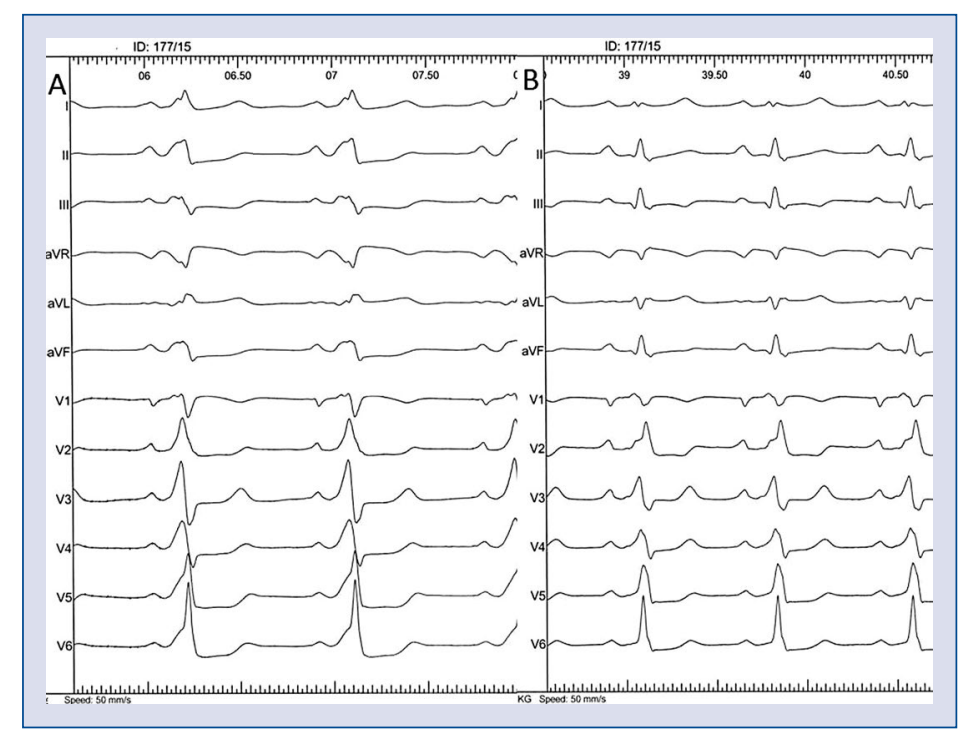

Figure 1. Baseline 12 lead electrocardiogram (A) and electrocardiogram after the radiofrequency ablation of 3 accessory pathways (B).

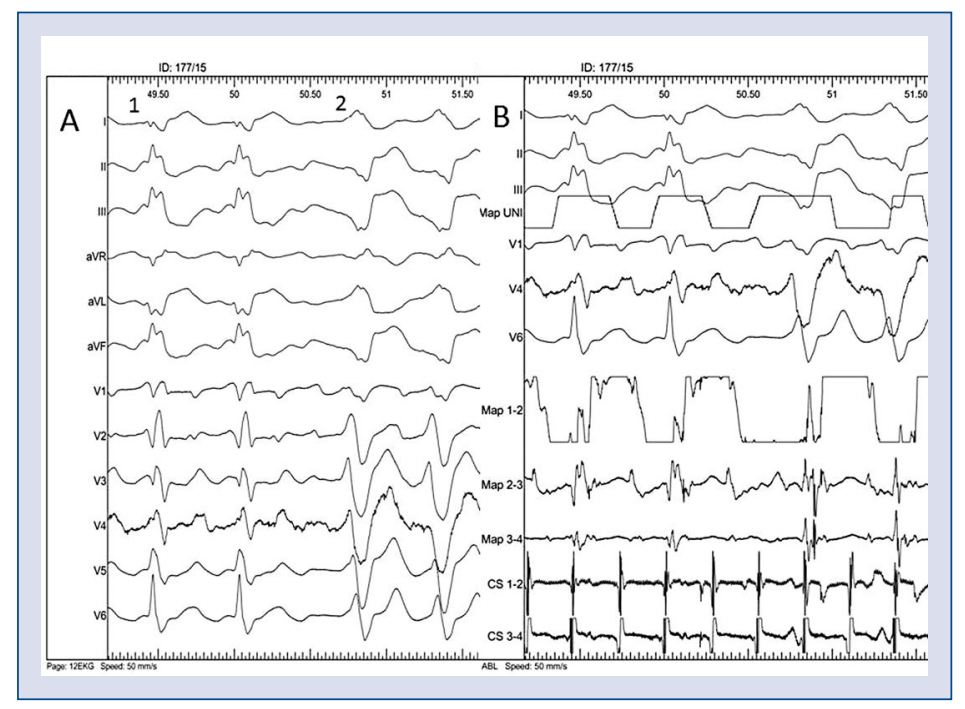

Figure 2. 12 lead electrocardiogram (A) and intracardiac recording (B) of cavotricuspid isthmus-dependent atrial flutter conducted through 2 accessory pathways, left posterosuperior (1) and broad right inferior/paraseptal (2).

24-h Holter-ECG monitoring, echocardiography, electrophysiological study parameters and coronary angiography in patients with the risk factors for ischemic heart disease. Mean left ventricular ejection fraction was $62.2 \%$.

Sixteen patients underwent ablation with the use of CARTO XP or CARTO 3 system (Biosense Webster) and 2 patients using EnSite ${ }^{\mathrm{TM}} \mathrm{NavX}$ (St. Jude Medical). Four patients treated in the 1990s underwent ablation without a 3-dimensional navigation system.
The mean procedure time was $155.0 \pm 74.0$ (range 60-240) $\mathrm{min}$, the mean fluoroscopy time was $10.1 \pm 3.6 \mathrm{~min}$ and mean fluoroscopy exposure $90.5 \pm 82.2 \mathrm{mGym}^{2}$.

Twenty-two patients with AP had 40 RFCA (mean 1.8; range 1-4), 33 of them at the centre (mean 1.5; range 1-3). Eighteen (81.8\%) patients had overt pre-excitation, $1(4.6 \%)$ intermittent and $3(13.6 \%)$ had concealed AP. Thirty-two APs (3 left-sided) were targeted with ablation. 


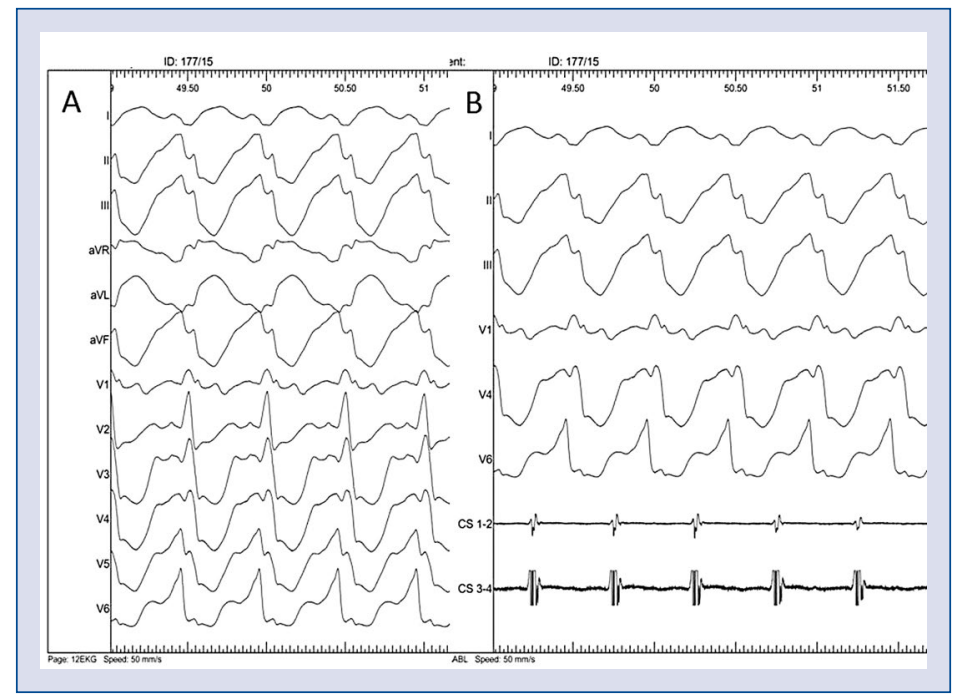

Figure 3. 12 lead electrocardiogram (A) and intracardiac recordings (B) of antidromic atrioventricular reentrant tachycardia conducted through left posteroinferior accessory pathway.

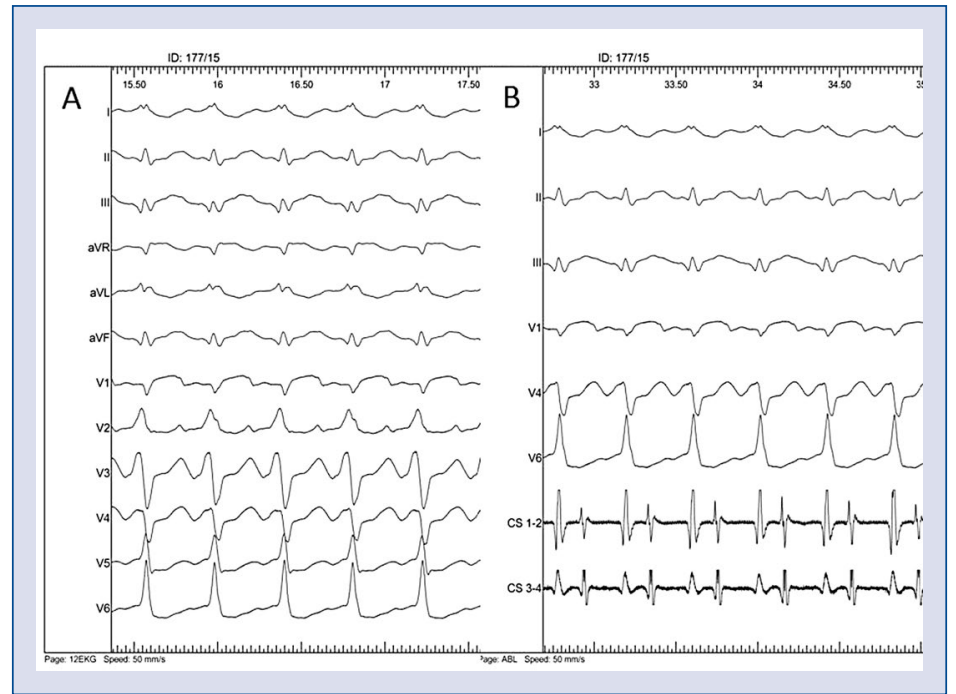

Figure 4. 12 lead electrocardiogram (A) and intracardiac recordings (B) of orthodromic atrioventricular reentrant tachycardia conducted through left posteroinferior accessory pathway.

Eight (36.4\%) patients had multiple APs, $11(50.0 \%)$ patients had broad AP. Three (13.6\%) patients had 3 APs (Figs. 1-4).

All patients with APs had palpitations or documented arrhythmias (mean age at the time of first episode $6.9 \pm 5.6$; range $1-16$ years). Twenty patients had documented orthodromic atrioventricular reciprocating tachycardia (O-AVRT), 5 antidromic atrioventricular reciprocating tachycardia (A-AVRT), 3 patients had slow/fast atrioventricular nodal reciprocating tachycardia (s/f AVNRT), 1 atrial flutter (CTI-AFL).
In 1 patient with $\mathrm{AP}$ and CTI-AFL, there was a failure to block the CTI during first procedure, (Table 1, Patient no. 11) during the second procedure the CTI was successfully blocked.

Three patients had O-AVRT and A-AVRT episodes, 2 patients only A-AVRT.

One patient with 3 APs had ventricular fibrillation (VF) episode and was considered as an end point of the first arrhythmic event. Eight (36.4\%) patients with APs had more than one type of arrhythmia, 1 patient had 3 types (4.5\%). Four patients had a history of cardiac surgery (Fig. 5; Table 3). 


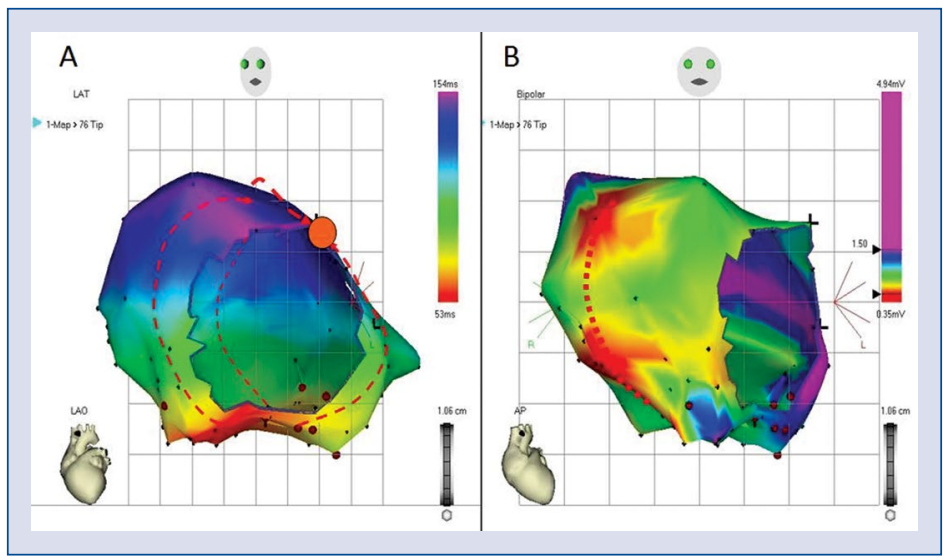

Figure 5. 18-year-old patient with Ebstein's anomaly after atrial septal defect and ventricular septal defect operation. Electroanatomical CARTO map of orthodromic atrioventricular reentrant tachycardia (A), bipolar voltage of the right atrium shows, probably post incisional, low voltage area (B).

Table 3. Patients with a history of cardiac surgery.

\begin{tabular}{|c|c|c|c|c|c|c|c|}
\hline Pt. & $\begin{array}{l}\text { Number } \\
\text { of surgical } \\
\text { procedures } \\
\text { prior to RF }\end{array}$ & $\begin{array}{c}\text { Surgical } \\
\text { procedures }\end{array}$ & Arrhythmias & Ablation & $\begin{array}{l}\text { Number } \\
\text { of RF } \\
\text { ablations }\end{array}$ & $\begin{array}{l}\text { Time from } \\
\text { surgery } \\
\text { to first RF } \\
\text { [years] }\end{array}$ & $\begin{array}{c}\text { Arrhythmia } \\
\text { during } \\
\text { follow-up }\end{array}$ \\
\hline 1 & 1 & $\begin{array}{l}\text { ASD closure, } \\
\text { VSD closure, } \\
\text { PDA closure }\end{array}$ & O-AVRT & $\begin{array}{l}\text { MAP, } \\
\text { inferoparaseptal } \\
\text { and right inferior }\end{array}$ & 1 & 17 & No \\
\hline 2 & 1 & TVR & A-AVRT & $\begin{array}{c}\text { Large AP, } \\
\text { inferoparaseptal- } \\
\text {-inferior }\end{array}$ & 3 & 1 & No \\
\hline 3 & 1 & $\begin{array}{l}\text { Coarctaction } \\
\text { of aorta }\end{array}$ & O-AVRT & $\begin{array}{l}\text { Inferoparaseptal } \\
\text { and CTI line } \\
\text { (uncompleted } \\
\text { line) }\end{array}$ & 2 & 36 & No \\
\hline 4 & 1 & $\begin{array}{c}\text { TVR, } \\
\text { cryoablation }\end{array}$ & $\begin{array}{l}\text { O-AVRT, } \\
\text { A-AVRT }\end{array}$ & $\begin{array}{l}\text { Large } A P \text {, right } \\
\text { inferior/right } \\
\text { antero-inferior }\end{array}$ & 3 & NA & AF \\
\hline
\end{tabular}

AF — atrial fibrillation; AP — accessory pathway; ASD — atrial septal defect; CTI — cavotricuspid isthmus; MAP — multiple accessory pathway; NA — not available; O-AVRT — orthodromic atrioventricular reciprocating tachycardia; PDA — patent ductus arteriosus; RF — radiofrequency; TVR — tricuspid valve replacement; VSD — ventricular septal defect

The success rate of RF ablation (RFA) in patients with APs after the first procedure conducted in this centre was $77.3 \%$ and after the last RFA the rate was $95.5 \%$.

In the group of 7 patients who underwent 3 or more RF procedures, there were 5 patients with whom the first 2 attempts which were not performed at this centre.

Three patients with APs and induced s/f AVNRT also underwent ablation of the slow $\mathrm{AV}$ node pathway. No major early or late complications were observed.

\section{Follow-up}

Long-term follow-up was done in 19 (86.4\%) patients with a median of $95.7 \pm 49.8$ (range 10-204) months after the first ablation procedure. Three patients who were treated in the mid-1990s were lost to follow-up.

After successful ablation, the antiarrhythmic drugs were discontinued.

One patient died due to heart failure during the follow-up at the age of 72 one year after a third unsuccessful RFA and 13 years after unsuccessful 
surgical cryoablation, which was performed during implantation of tricuspid valve prosthesis and suture of an atrial septal defect.

One patient with WPW and VF, after successful RFA of the APs, did not experience any arrhythmia episodes.

The long-term success rates were $95.5 \%$ of patients with APs, and $100 \%$ in patients with AVNRT and CTI-AFL.

\section{Discussion}

There remains a limited number of previously published reports concerning long-term follow-up data in patients with EA and arrhythmias treated RFA.

Data of patients with EA and RFCA of APs which were published previously reported a relatively short follow-up from $12 \pm 7$ to $54 \pm 34$ months $[3,4,12,14]$.

Apparently the present study has the longest follow-up and one of the largest cohort of patients with EA and APs.

The clinical outcome of this study indicates that in long-term follow-up after successful ablation, the majority of patients were free of any arrhythmia episodes, ablated as well as newly developed.

The ablation of AP in patients with EA is challenging but when performed in an experienced centre the long-term follow-up is satisfactory.

Some authors have suggested the use of intracardiac echo to define the true location of tricuspid annulus (TA) via the right coronary artery (RCA) [18].

Others have proposed the use of guidewire or diagnostic catheter inserted into the RCA for proper delineation or mapping of TA [14].

These two prior techniques were not used in this study. Since 2002, this clinic has routinely used a 3-dimensional system, $8 \mathrm{~F}$ irrigated tip catheter and long sheaths and, if necessary, with 180 degree curvature.

The presented outcomes (77.2\% efficacy after the first and $95.5 \%$ after the last procedure) are comparable to those reported in an earlier series $[4,6,12]$.

The percentage of patients with EA and multiple accessory pathway in this study was similar to those presented by other authors [3, 5, 12, 14].

Contrary to other studies, however, a very high percentage of patients with broad APs (50\%) was found. The presence of a broad AP in a particular patient can be subjective is consequently difficult to quantify.
The current guidelines itemised EA as a risk factor for $\mathrm{VF}$ in patients with $\mathrm{AP}$ but in a previous study conducted on the largest cohort of patients with aborted sudden cardiac death and APs thus far, EA was not defined as a statistically significant risk factor for VF $[11,19]$.

\section{Limitations of the study}

This is a retrospective analysis and therefore several limitations must be taken into account. The main limitations of the present study are the relatively small number of patients enrolled. Secondly, not all detailed data concerning ablation procedures were available. Thirdly, precise echocardiographic data of patients who underwent ablation in the 1990s were not always available. Fourthly, some patients were lost to follow-up.

\section{Conclusions}

The RFAs in patients with EA and APs are challenging but most arrhythmias are amenable to ablation and long-term follow-up is well recommended.

\section{Acknowledgements}

This manuscript has not been previously published, some data included in the manuscript were presented as an abstract at the $43^{\text {rd }}$ Annual Meeting of the Association for European Paediatric Cardiology, May 21-24 2008 in Venice.

\section{Conflict of interest: None declared}

\section{References}

1. Jost CHA, Connolly HM, Dearani JA, Edwards WD, Danielson GK. Ebstein's anomaly. Circulation, 2007; 115: 277-285.

2. Khositseth A, Danielson GK, Dearani JA, Munger TM, Porter CJ. Supraventricular tachyarrhythmias in Ebstein's anomaly: management and outcome. J Thorac Cardiovasc Surg, 2004; 128: 826-833.

3. Delhaas T, Sarvaas GJ, Rijlaarsdam ME et al. A multicenter, long-term study on arrhythmias in children with Ebstein's anomaly. Pediatr Cardiol, 2010; 31: 229-233.

4. Reich JD, Auld D, Hulse E, Sullivan K, Campbell R. The pediatric radiofrequency ablation registry's experience with Ebstein's anomaly. Pediatric Electrophysiology Society. J Cardiovasc Electrophysiol, 1998; 9: 1370-1377.

5. Chetaille P, Walsh EP, Triedman JK. Outcomes of radiofrequency catheter ablation of atrioventricular reciprocating tachycardia in patients with congenital heart disease. Heart Rhythm, 2004; 1: 168-173.

6. Roten L, Lukac P, DE Groot N et al. Catheter ablation of arrhythmias in Ebstein's anomaly: a multicenter study. J Cardiovasc Electrophysiol, 2011; 12: 1391-1396. doi: 10.1111/j.15408167.2011.02161.x. 
7. Sherwin ED, Triedman JK, Walsh EP. Update on interventional electrophysiology in congenital heart disease: evolving solutions for complex hearts. Circ Arrhythm Electrophysiol, 2013; 6: 1032-1040. doi: 10.1161/CIRCEP.113.000313.

8. Van Lingen B, Baverfeld SR. The electrocardiogram in Ebstein's anomaly of tricuspid valve. Am Heart J, 1995; 50: 13-23.

9. Iturralde $\mathrm{P}$, Nava $\mathrm{S}$, Sálica $\mathrm{G}$ et al. Electrocardiographic characteristics of patients with Ebstein's anomaly before and after ablation of an accessory atrioventricular pathway. J Cardiovasc Electrophysiol, 2006; 17: 1332-1336.

10. Baumgartner H, Bonhoeffer P, De Groot NM et al. Task Force on the Management of Grown-up Congenital Heart Disease of the European Society of Cardiology (ESC); Association for European Paediatric Cardiology (AEPC); ESC Committee for Practice Guidelines (CPG). ESC Guidelines for the management of grownup congenital heart disease. Eur Heart J, 2010; 23: 2915-2957.

11. Blomström-Lundqvist C, Scheinman MM, Aliot EM, et al. ACC/ /AHA/ESC guidelines for the management of patients with supraventricular arrhythmias: executive summary: a report of the American College of Cardiology/American Heart Association Task Force on Practice Guidelines and the European Society of Cardiology Committee for Practice Guidelines. Circulation 2003; 108: 1871-1909.

12. Wei W, Zhan X, Xue Y, et al. Features of accessory pathways in adult Ebstein's anomaly. Europace 2014; 16: 1619-1625.
13. Guo XG, Liu XU, Zhou GB, Ma J, Ouyang F, Zhang S. Frequency of fractionated ventricular activation and atrial/ventricular electrogram amplitude ratio at successful ablation target of accessory pathways in patients with Ebstein's anomaly. J Cardiovasc Electrophysiol, 2015; 26: 404-411. doi: 10.1111/jce.12607.

14. Cappato R, Schlüter M, Weiss C et al. Radiofrequency current catheter ablation of accessory atrioventricular pathways in Ebstein's anomaly. Circulation, 1996 1; 94: 376-383.

15. Attenhofer Jost CH, Connolly HM, Dearani JA, Edwards WD, Danielson GK. Ebstein's anomaly. Circulation, 2007; 115: 277-285.

16. Weng KP, Wolff GS, Young ML. Multiple accessory pathways in pediatric patients with Wolff-Parkinson-White syndrome. Am J Cardiol, 2003; 91: 1178-1183.

17. Sacher F, Wright M, Tedrow UB, et al. Wolff-Parkinson-White ablation after a prior failure: a 7-year multicentre experience. Europace, 2010; 12: 835-841. doi: 10.1093/europace/euq050.

18. Vukmirović M, Peichl P, Kautzner J. Catheter ablation of multiple accessory pathways in Ebstein anomaly guided by intracardiac echocardiography. Europace, 2016; 18: 339. doi: 10.1093/ europace/euv428.

19. Orczykowski M, Walczak F, Derejko P et al. Ventricular fibrillation risk factors in over one thousand patients with accessory pathways. Int J Cardiol, 2013; 167: 525-530. doi: 10.1016/j.ijcard.2012.01.076. 